\title{
Module 1: Review and Mathematics
}

\author{
Christopher P Oertel, Bryon P Marsh
}

March 2019

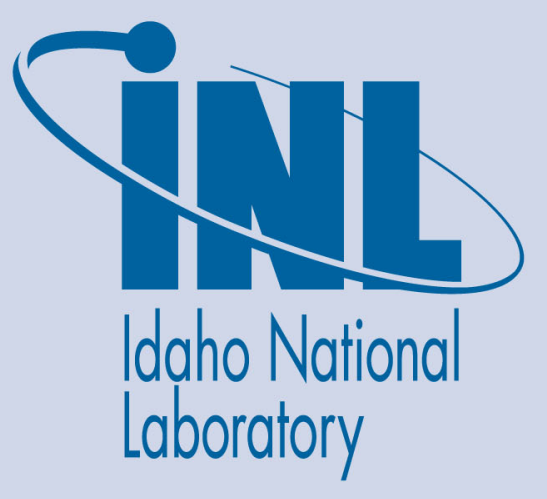

The INL is a U.S. Department of Energy National Laboratory operated by Battelle Energy Alliance 


\title{
Module 1: Review and Mathematics
}

\author{
Christopher P Oertel, Bryon P Marsh
}

March 2019

Idaho National Laboratory Idaho Falls, Idaho 83415

http://www.inl.gov

Prepared for the U.S. Department of Energy Office of Nuclear Energy Under DOE Idaho Operations Office

Contract DE-AC07-05ID14517 


\section{RAD Review and Mathematics}

Advanced Radiological Detection Training WMD-Civil Support Team, 2019

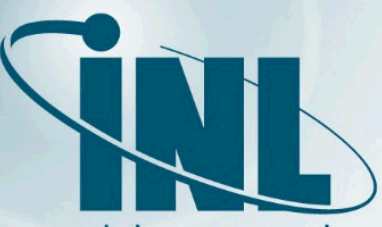




\section{Objectives}

- Review basic radiation concepts

- Identify common radiation exposure sources

- Discuss methods to protect against exposure to radiation

- Describe common commercial sources of radiation and radioactive materials

- Basic units and conversions

- How to use basic conversions in order to determine needed answers

- The inverse-square law

- The concept of half-value layers

- Activity Calculations 


\section{The Los Alamos Radiation Monitoring Notebook}

- The Los Alamos Radiation Monitoring Notebook is one of the best tools you can carry with you.

- This handbook, written and produced by James T. (Tom) Voss, has nearly all the information anyone would need when it comes to working around radiological sources.

Los Alamos

Radiation Monitoring

Notebook

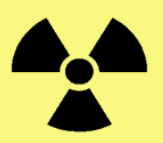

LA-UR-00-2584

James T. (Tom) Voss, NRRPT, CHP

June 2000 


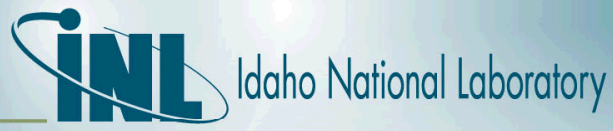

\section{Rad review}

- Atom structure

- Stability/decay

- Radiation vs contamination

- Activity and decay chain

atomic mass

chemical symbol
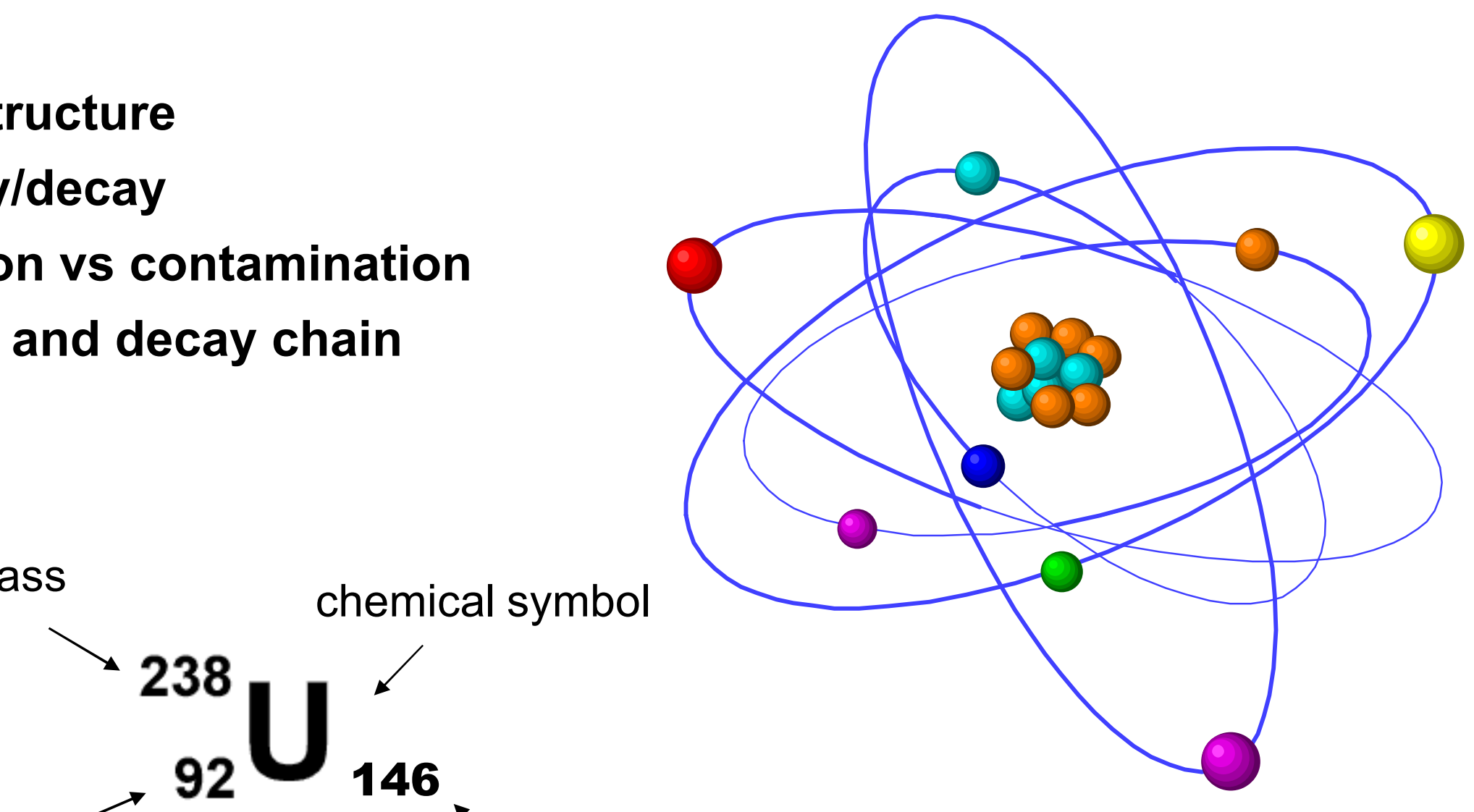

neutron number 


\section{TID Idaho National Laboratory}

\section{Terminology}

- Isotope: species of particular element identified by number of neutrons in nucleus.

- Radionuclide: generic term for radioactive isotope of element.

- Radioactive Decay: the process by which unstable atoms release energy, in the form of particles and rays, to become stable (nonradioactive) 


\section{TII Idaho National Laboratory}

\section{Terminology}

- Curie (Ci) - unit of radioactivity equal to 3.7 E10 disintegrations per second

- Specific Activity - the amount of radioactivity (Ci) per unit mass (usually grams) of a radionuclide 


\section{Terminology}

- lonizing radiation: radiation that causes atoms to lose electrons $(\alpha, \beta, \gamma, X, \eta)$.

- Radioactive material: material that emits ionizing radiation.

- Contamination: radioactive material where you don't want it. 


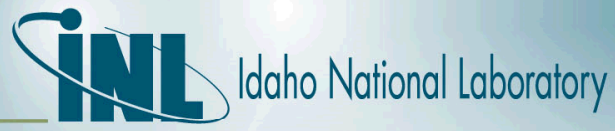

\section{Radiation}

- Alpha, Beta, Gamma, Neutron

- Detection, Decon \& PPE

- Time Distance and Shielding

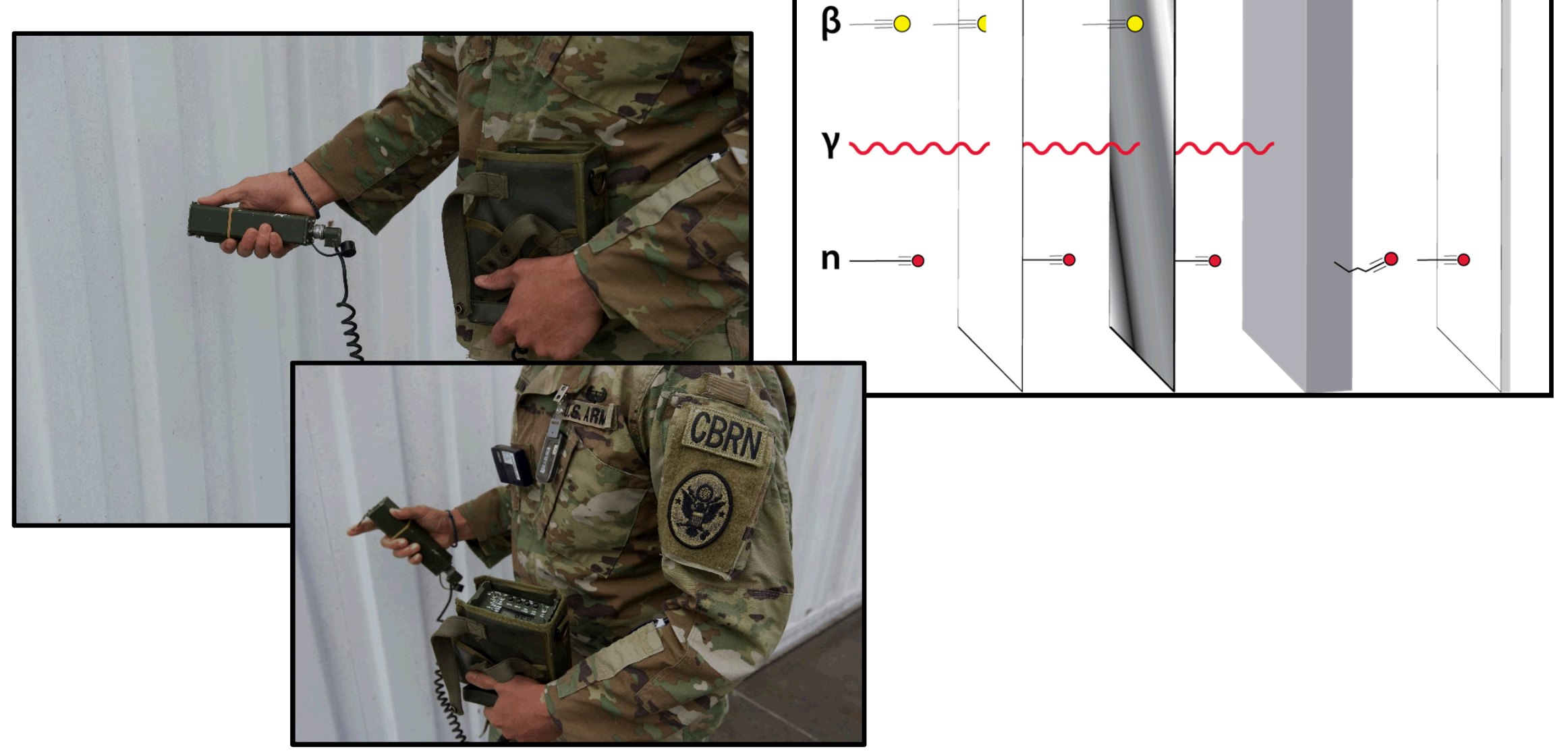




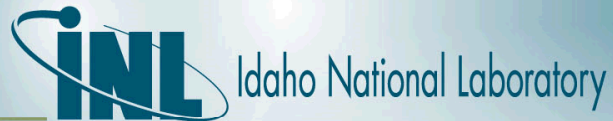

\section{Gamma Spectrum \& Energy/Peak Review}

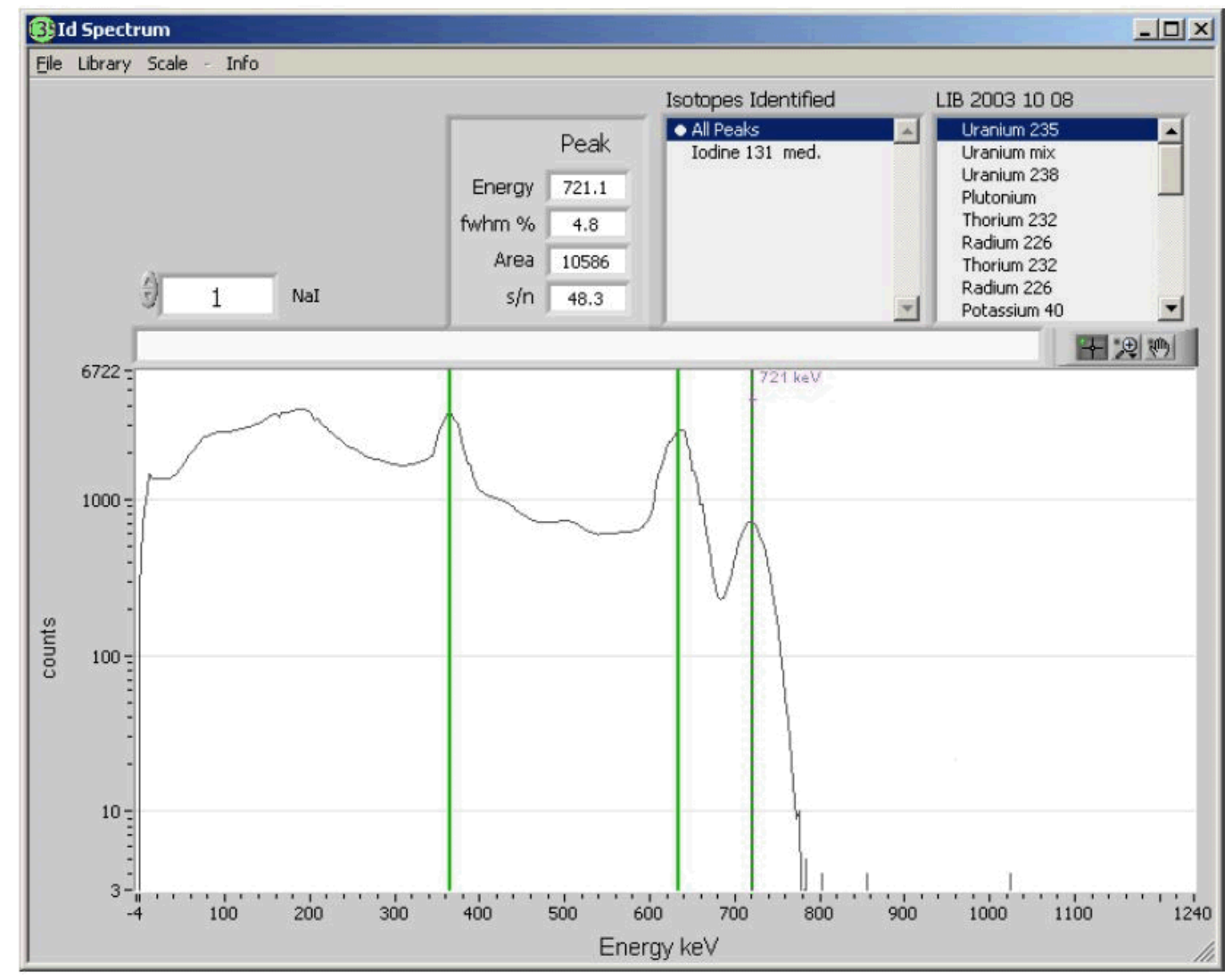




\section{Source Review}

- Naturally Occurring Radioactive Material (NORM)

- Radon \& Uranium ore are examples

- Industrial

$-{ }^{137} \mathrm{Cs},{ }^{60} \mathrm{Co},{ }^{90} \mathrm{Sr},{ }^{192} \mathrm{Ir},{ }^{75} \mathrm{Se}$

- Medical

- ${ }^{99}$ Tc, ${ }^{123} \mathbf{I},{ }^{131} \mathrm{I},{ }^{67} \mathbf{G a}$

$-{ }^{18} \mathrm{~F},{ }^{111}$ In

- Special Nuclear Material (SNM)

- ${ }^{239} \mathrm{Pu},{ }^{233} \mathrm{U}$ and ${ }^{235} \mathrm{U}$

- RDD: things to consider

- Form

- Availability

- Dispersal

- Energy

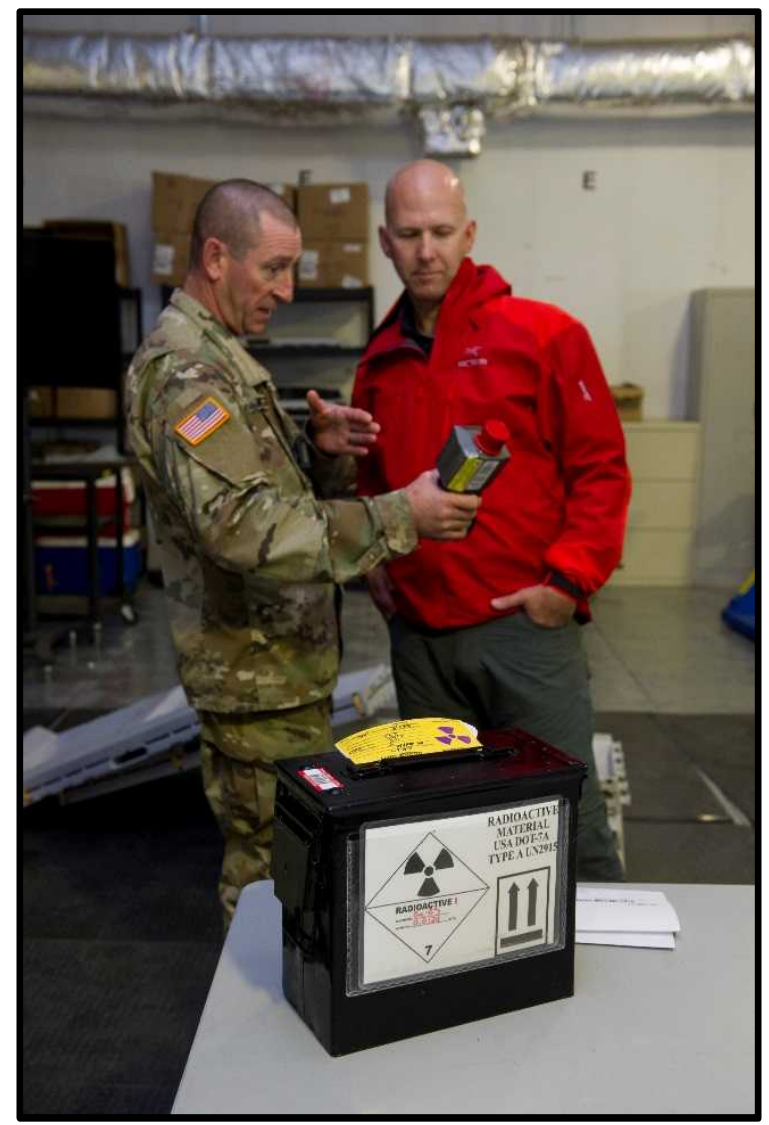




\section{Dosimetry Terms and Units}

- Roentgen (R): Exposure unit regarding $\chi$ or $\gamma$

- RAD: Absorbed dose unit regarding $\alpha, \beta, \gamma$, or $\eta$

- Gray (Gy): SI Absorbed dose unit

- REM: Dose equivalent unit

- $1 \mathrm{RAD}=0.01 \mathrm{~Gy}(1 \mathrm{cGy})=1 \mathrm{R}(\chi$ or $\gamma)$

- 1 REM = 1 RAD $(\beta$ or $\gamma)$

- 1 REM = 1000 mREM $\left(10^{-3}\right)=1,000,000 \mu \operatorname{REM}\left(10^{-6}\right)$ 


\section{Radiation Weighting (or Quality) Factors: RAD to REM}

\begin{tabular}{|l|c|}
\hline Radiation & $\omega_{\mathrm{r}}$ \\
\hline Gamma & 1 \\
\hline Beta & 1 \\
\hline Alpha & 20 \\
\hline Neutron & $5-20$ \\
\hline X-Ray & 1 \\
\hline
\end{tabular}




\section{Typical Doses}

- Average Annual Exposure

- Chest x-ray

620 mrem per year

10 to $30 \mathrm{mrem}$

- Airline Flight

- Smoking 1.5 packs / day to the lung

- LD50/30

0.5 mrem every hour 16,000 mrad per year

400-450 rem acute whole body

rad $=$ rem $=$ Roentgen (these three units can be considered equivalent for this training)

$$
1 \mathrm{rem}=1000 \mathrm{mrem} \quad 1 \mathrm{rem} / \mathrm{hr}=1000 \mathrm{mrem} / \mathrm{hr}
$$

For your training the limit is set at no more than $\mathbf{5 0}$ mrem per day 


\section{Emergency Worker Exposure Guidelines}

\begin{tabular}{|c|c|c|}
\hline Dose Limit (rem) & Activity & Condition \\
\hline $0-5$ & all & none \\
\hline $5-10$ & $\begin{array}{l}\text { protecting } \\
\text { valuable property }\end{array}$ & $\begin{array}{l}\text { voluntary; low } \\
\text { dose not } \\
\text { practicable }\end{array}$ \\
\hline $10-25$ & $\begin{array}{l}\text { Lifesaving, or } \\
\text { protecting large } \\
\text { populations }\end{array}$ & $\begin{array}{l}\text { voluntary; low } \\
\text { dose not } \\
\text { practicable }\end{array}$ \\
\hline$>25$ & $\begin{array}{l}\text { Lifesaving, or } \\
\text { protecting large } \\
\text { populations }\end{array}$ & $\begin{array}{l}\text { Only voluntary } \\
\text { basis with } \\
\text { informed risk }\end{array}$ \\
\hline
\end{tabular}

PAG Manual, EPA-400/R-17/001, Table 3-1 


\section{Dose Limits: DA PAM 40-18}

(1) Ensure the rescuer's dose equivalent does not exceed 100 rems (1000 mSv).

(2) Brief the rescuer on the potential acute and on the statistically inferred increased risk of cancer from doses that may be incurred during the rescue operation.

(3) Ensure that the rescuer is a volunteer and is fully informed of the risk if the expected rescue exposure is above $25 \mathrm{rem}$.

Also see U.S. Environmental Protection Agency (EPA) Guide EPA-400/R$17 / 001$.

Table 4-1

Dosimeter results that require notification of OTSG $(\mathrm{mrem})(1)$

Body parts

Quarterly monitor- Monthly monitoring

ing

Whole bodv ${ }^{2}$

1250

400 


\section{Stay Time}

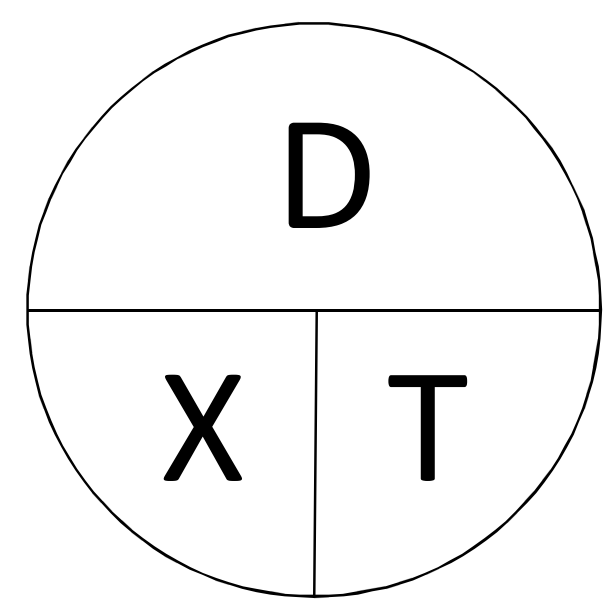

D: Dose

$X$ : Dose Rate

T: Time

- Stay time is defined as, "the maximum amount of time allowed for a body (animate or inanimate) to remain at a location in order to receive a maximum prescribed dose."

- In our work, stay time is important when considering the maximum amount of radiation dose a person is allowed to absorb.

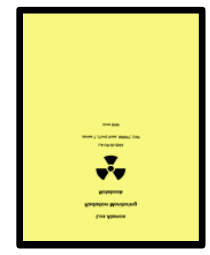

Page 54 


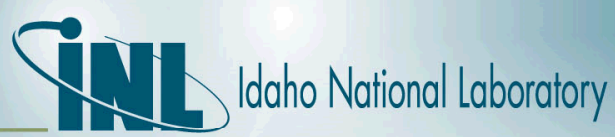

\section{Stay Time}

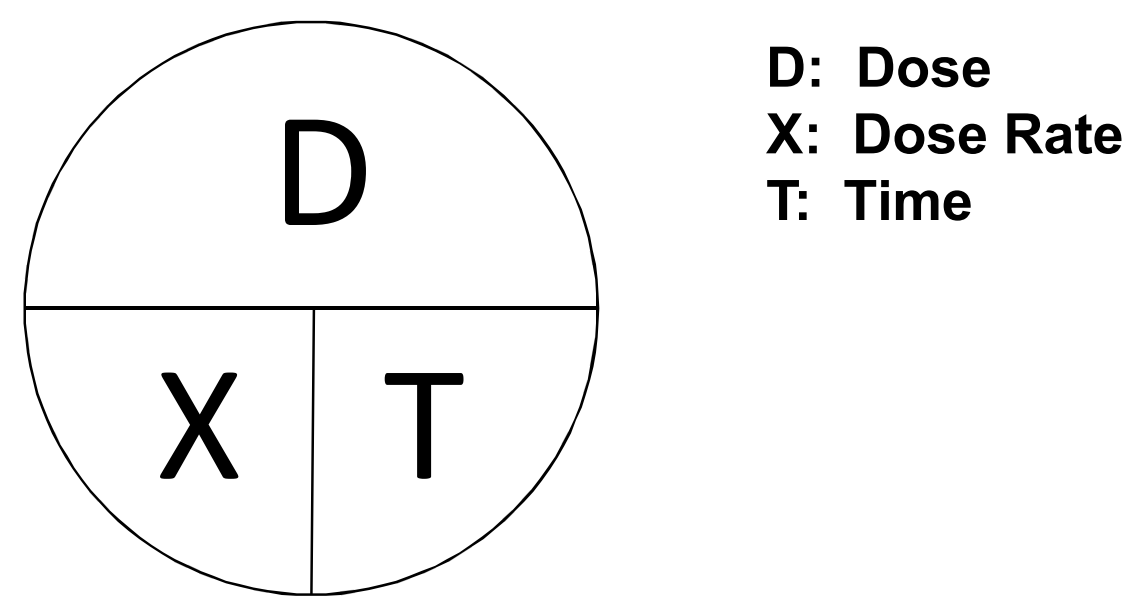

- Dose $=$ dose rate $x$ time e.g. $\mathrm{mR} / \mathrm{hr} \times \mathrm{hr}=\mathrm{mR}$

- Dose rate $=$ dose/time e.g. $\mathrm{mR} / \mathrm{sec}$

- Time $=$ dose/dose rate e.g. $R / R / h r=h r$ 


\section{Stay Time}

- Stay time is easily calculated if the maximum dose allowed and source intensity are known.

- For example, your RSO has set the monthly dose limit at $400 \mathrm{mR}$.

- How long would it take a worker to receive this dose from a source that gave off $20 \mathrm{R} / \mathrm{hr}$ ? 


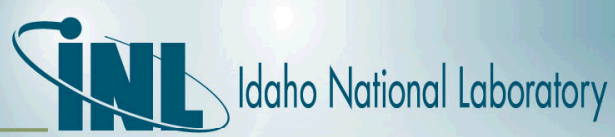

\section{Stay Time}

- $\mathrm{T}=\mathrm{Dose} / \mathrm{dose}$ rate

- Dose Rate $=20 \mathrm{R} / \mathrm{hr}=20,000 \mathrm{mR} / \mathrm{hr}$ - NOTICE UNITS CONVERSION!!

- Time allowed $=400 \mathrm{mR} / 20,000 \mathrm{mR} / \mathrm{hr}=0.02 \mathrm{hr}=72 \mathrm{sec}$ 


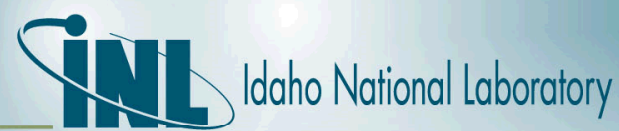

\section{The Inverse Square Law}

- The Inverse Square Law (ISL) is a law of physics that allows for the determination of the intensity of sound, radiation, light and other physical particles at different distances from the source.

- With respect to radiation sources, the ISL allows for the calculation of either;

- Dose rate at a second distance or,

- The distance that would give a desired alternative dose rate.

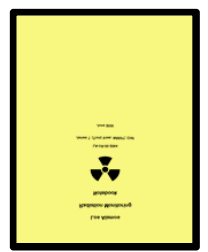

Page 63

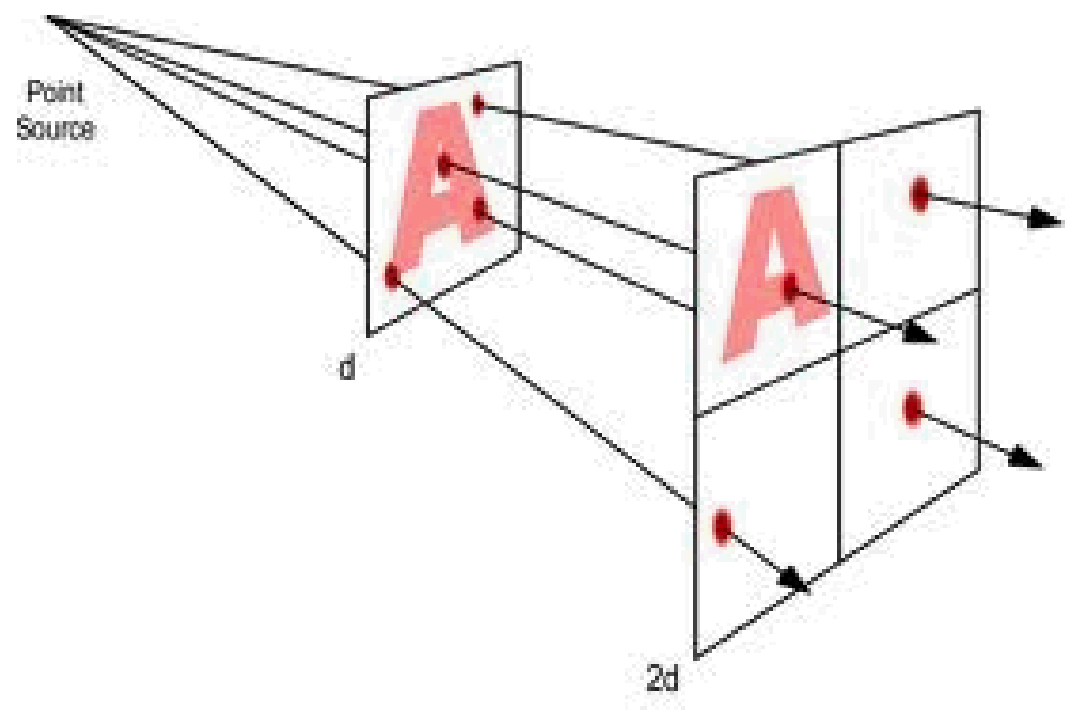




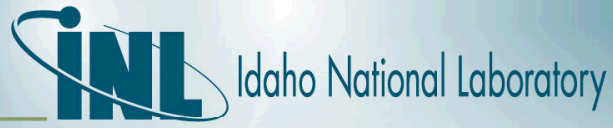

\section{Basic Rules of Thumb for the ISL}

- Decrease your distance from the source by $1 / 2$ gives an increase in dose rate by a factor of 4

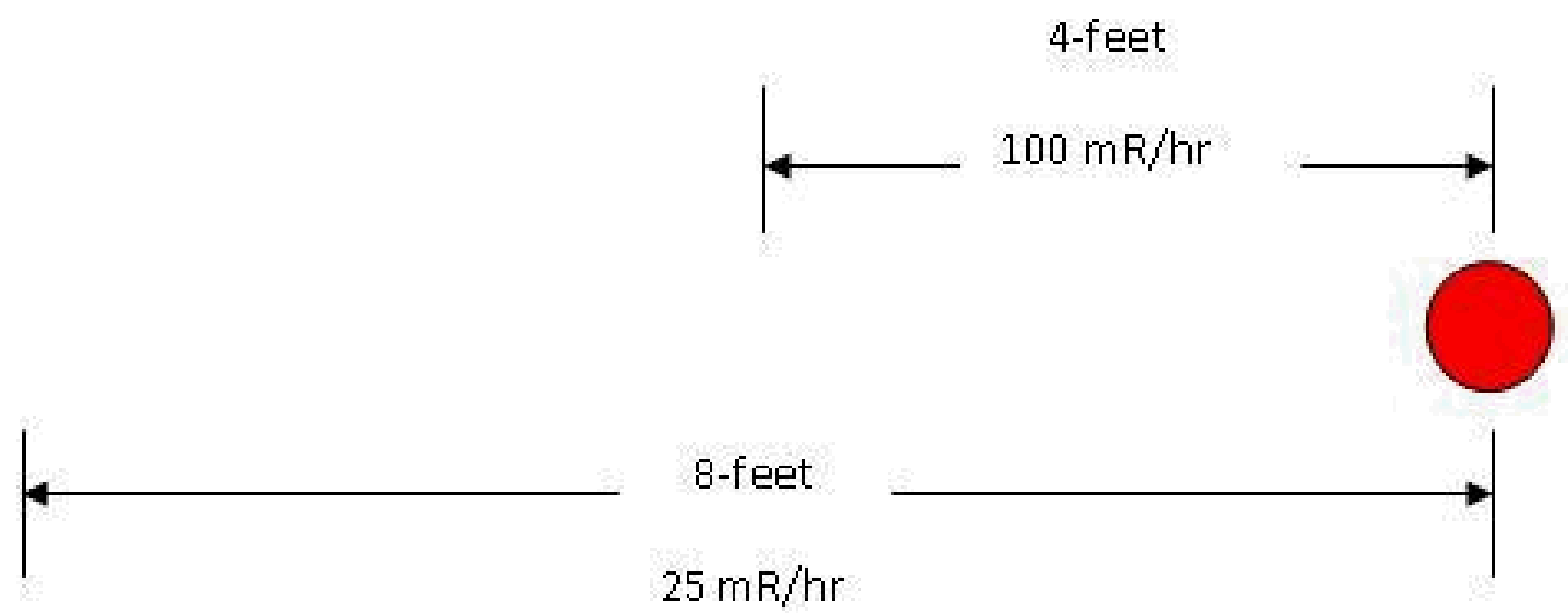




\section{The Inverse Square Law}

- The overall general equation is:

$$
X_{1} \times d_{1}^{2}=X_{2} \times d_{2}^{2}
$$

Where: $X_{1}$ is the dose rate at distance $1\left(d_{1}\right)$

And $X_{2}$ is the dose rate at distance $2\left(d_{2}\right)$

- Important variations of the general equation are:

- To find the dose rate at a second distance use

$$
X_{2}=X_{1} \times \frac{d_{1}^{2}}{d_{2}^{2}}=X_{1} \times\left(\frac{d_{1}}{d_{2}}\right)^{2}
$$

- To find the distance at a desired dose rate use

$$
d_{2}=d_{1} \times \sqrt{\frac{X_{1}}{X_{2}}}=d_{1} \times\left(\frac{X_{1}}{X_{2}}\right)^{\frac{1}{2}}
$$




\section{The Inverse Square Law}

- There is a source that is giving off $100 \mathrm{R} / \mathrm{hr}$ at one foot. How far from the source would you have to stand in order for the dose rate to decrease to $25 \mathrm{mR} / \mathrm{hr}$ ?

- What are you being asked to solve for? Distance or Dose Rate?

- What form of the ISL will you use to get the desired answer?

- Why is it NOT important to identify the source if we're only asking about dose rate? 


\section{Inverse Square Law---- Steps}

- Manual calculation steps:

- Write out the four needed variables

$$
\begin{aligned}
& \times 1= \\
& D 1= \\
& \times 2= \\
& D 2=
\end{aligned}
$$

- Insert numeric values WITH units:

$$
\begin{aligned}
& X 1=100 \mathrm{R} / \mathrm{Hr} \\
& \mathrm{D} 1=1 \mathrm{ft} \\
& \mathrm{X} 2=25 \mathrm{mR} / \mathrm{hr} \\
& \mathrm{D} 2=?
\end{aligned}
$$




\section{Inverse Square Law}

- Select proper form of ISL to solve:

$$
d_{2}=d_{1} \times \sqrt{\frac{X_{1}}{X_{2}}}
$$

- Insert values and convert units

$$
d 2=1 f t\left(\frac{100 \frac{R}{h r}}{0.025 R / h r}\right)^{1 / 2}
$$




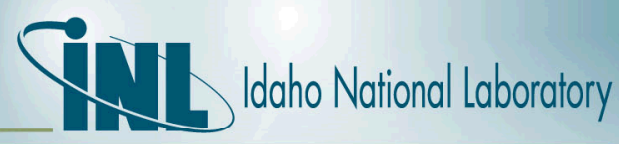

\section{Inverse Square Law}

- Cancel units and perform calculation:

$$
d 2=1 f t *\left(\frac{100 \frac{R}{h r}}{0.025 R / h r}\right)^{1 / 2}
$$

- $\mathrm{d} 2=63.2 \mathrm{ft}$

- Always evaluate the calculation: DOES IT MAKE SENSE?? 


\section{The Inverse Square Law}

- There is a source that is giving off a dose rate of $750 \mathrm{mR} / \mathrm{hr}$ at 3 feet. What would the dose rate be at 10 feet?

- What are you being asked to solve for? Distance or Dose Rate?

- What form of the ISL will you use? 


\section{Inverse Square Law---- steps}

- Manual calculation steps:

- Write out the four needed variables

$$
\begin{aligned}
& \times 1= \\
& D 1= \\
& \times 2= \\
& D 2=
\end{aligned}
$$

- Insert numeric values WITH units:

$$
\begin{aligned}
& \mathrm{X} 1=750 \mathrm{mR} / \mathrm{hr} \\
& \mathrm{D} 1=3 \mathrm{ft} \\
& \mathrm{X} 2=? \\
& \mathrm{D} 2=10 \mathrm{ft}
\end{aligned}
$$




\section{Inverse Square Law}

- Select proper form of ISL to solve:

$$
X_{2}=X_{1} \times \frac{d_{1}^{2}}{d_{2}^{2}}
$$

- Insert values and convert units

$$
\mathrm{x} 2=750 m r / h r\left(\frac{3 f t}{10 f t}\right)^{2}
$$




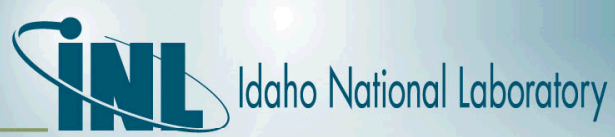

\section{Inverse Square Law}

- Cancel numerator/denominator units and do calculation:

$$
\mathrm{x} 2=750 \mathrm{mR} / \mathrm{hr}\left(\frac{3 \mathrm{ft}}{10 \mathrm{ft}}\right)^{2}
$$

- $\mathrm{X} 2=67.5 \mathrm{mR} / \mathrm{hr}$

- Always evaluate the calculation: DOES IT MAKE SENSE?? 


\section{Inverse Square Law—RadPro Calc}

- RadPro calculator can be run online or from download

- Main features include units convertor, gamma emitter/exposure rate, and inverse square law.

- Lets do problem 1 again using this software

radprocalculator.com 


\section{The Inverse Square Law}

- There is a source that is giving off $100 \mathrm{R} / \mathrm{hr}$ at one foot. How far from the source would you have to stand in order for the dose rate to decrease to $25 \mathrm{mR} / \mathrm{hr}$ ?

- What are you being asked to solve for? Distance or Dose Rate?

- What form of the ISL will you use to get the desired answer?

- Why is it NOT important to identify the source if we're only asking about dose rate? 


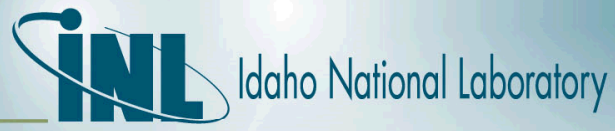

\section{RadPro Calc}

\section{Rad Pro Calculator}

Site Navigation Menu Home Page

Online Calculators $\gg$ Freeware

$\rightarrow$ Rad Pro Information $\gg$ Documents $\gg$ Help

For those needing portability, Rad Pro for Desktop works with Windows 8.1/10 tablets. Will not work with Surface tablets running Windows RT.

\section{Rad Pro Calculator Site Description and Details}

(Click on a title bar to expand and read the panel contents.)

1. General Site Description
Rad Pro Calculator online performs many nuclear calculations that are useful to the health physicist, radiological
researcher, radiochemist, radiation safety officer, health physics technician (HP) and other professionals in radiation
physics and radiological engineering. It calculates, among other things, radioactivty units conversions (SI and US
customary) and gamma emitter dose rate and activity.
2. Other Calculations
3. Other Uses
4. Online Calculator Access and Desktop/PDA Freeware Downloads
5. Disclaimer




\section{q}

\section{RadPro Calc}

- Open Online Calculators tab and make selection

- In this case choose Dose Rate, then Inverse Square Law

- Pay close attention to the units

- Enter data 


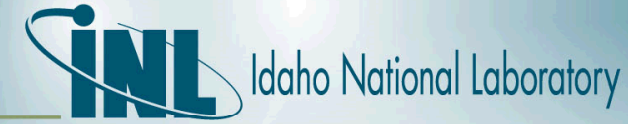

\section{Radpro Calculator}

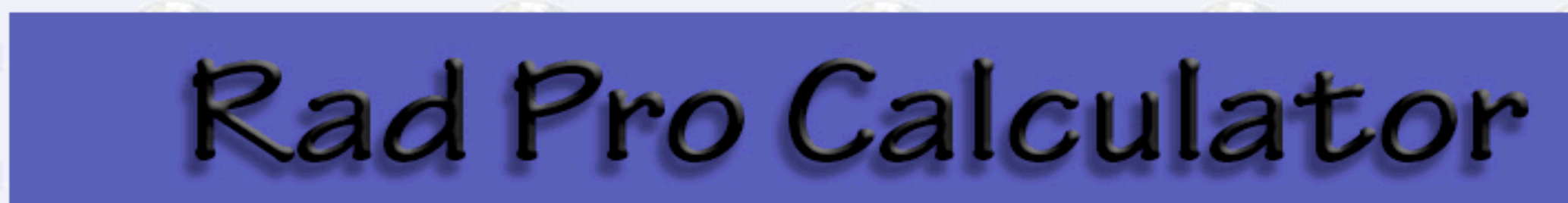

Site Navigation Menu Home Page $\quad$ Online Calculators $\gg \mid$ Freeware $\quad \gg \mid$ Rad Pro Information $\gg \mid$ Documents $\gg \mid$ Help $\quad \gg$

For those needing portability, Rad Pro for Desktop works with Windows 8.1/10 tablets. Will not work with Surface tablets running Windows $R$

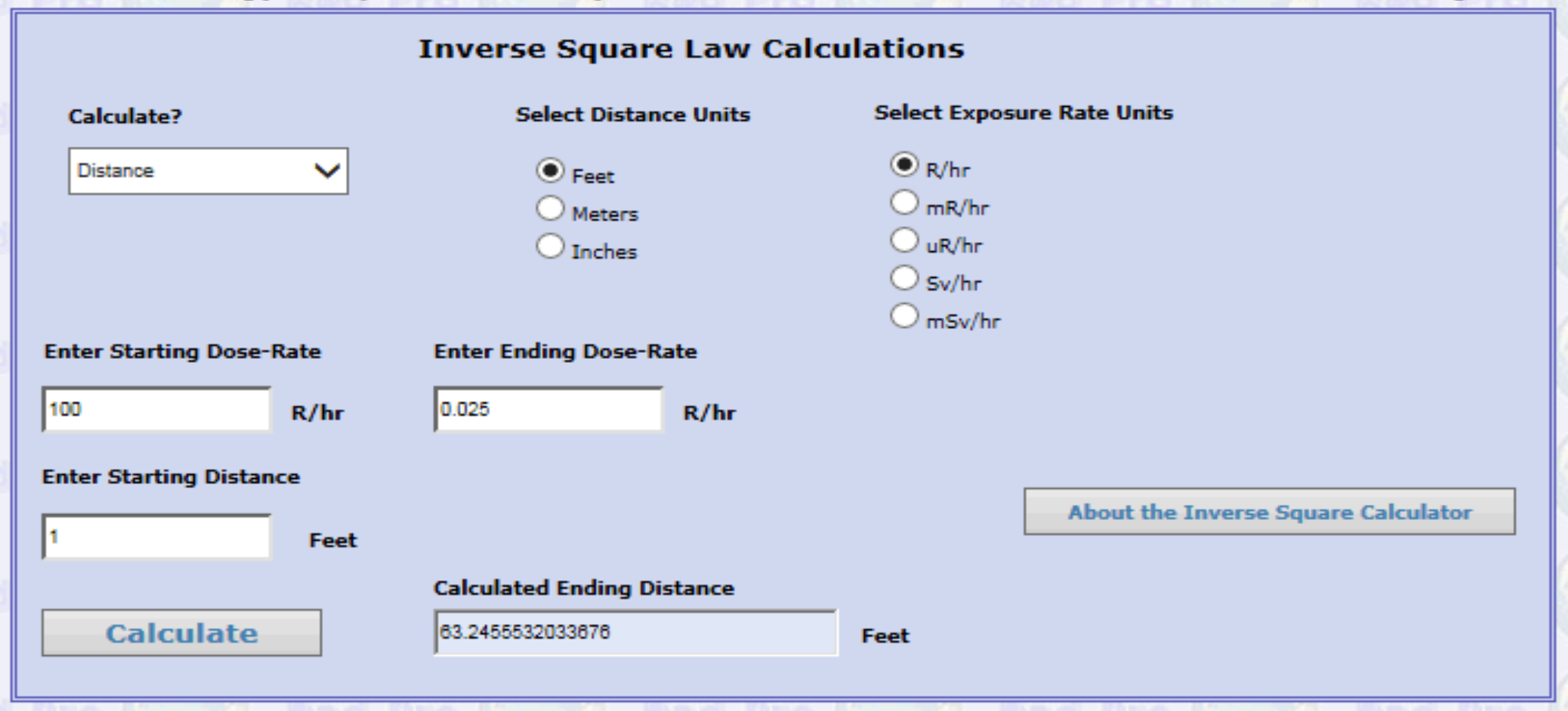




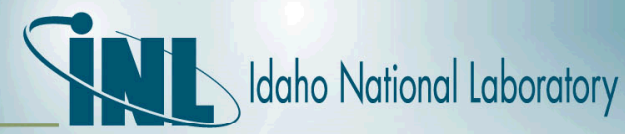

\section{Basic Rules of Thumb for the ISL}

- The ISL can also help you determine where a source is in a CONEX container or room

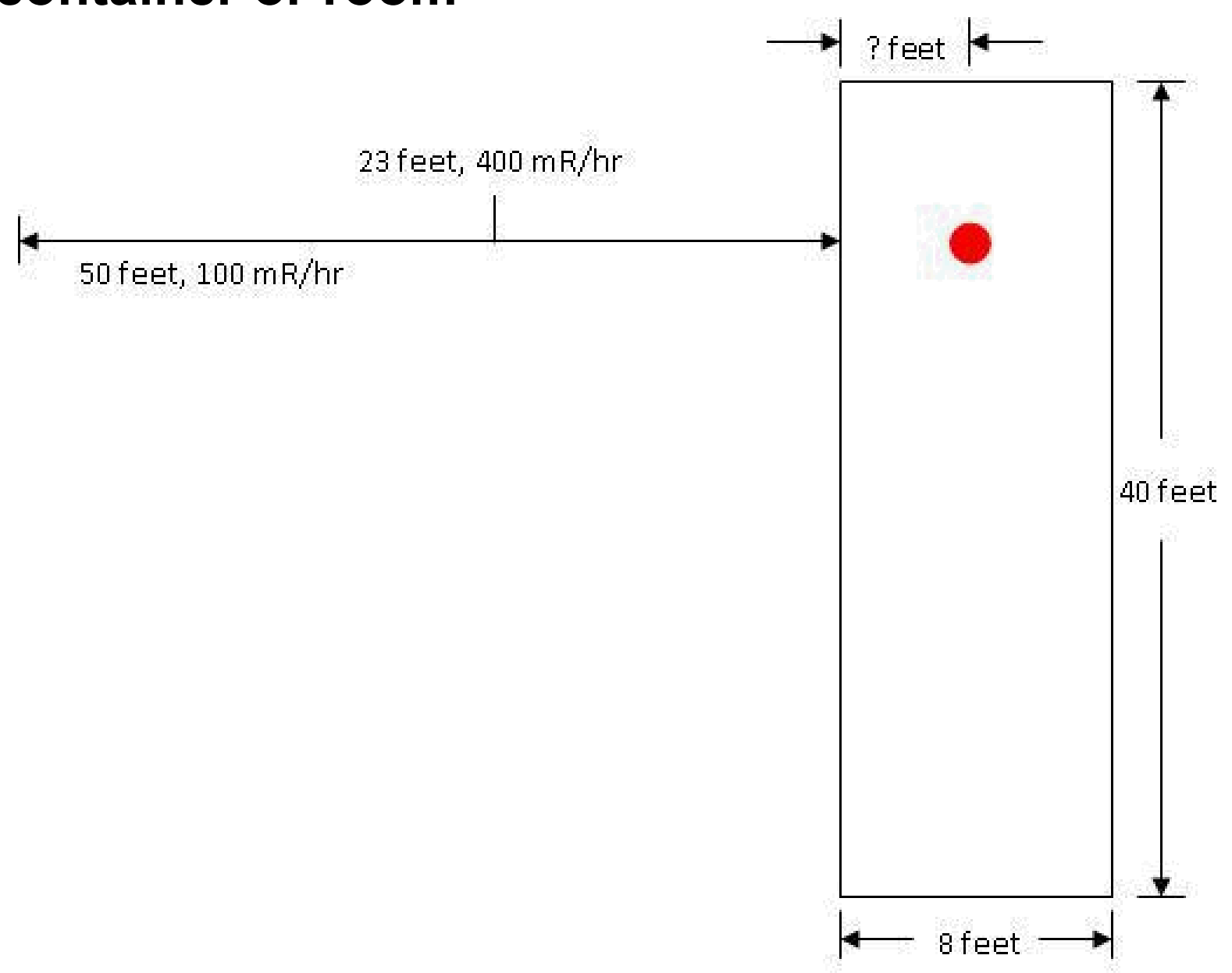




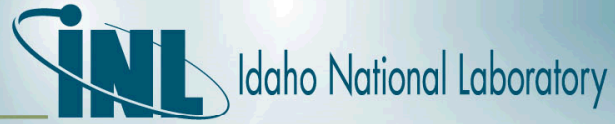

\section{Limitations of the Inverse Square Law}

- Point Source vs. Line Source

- A line source, on the other hand, gives off radiation in a cylindrical manner.

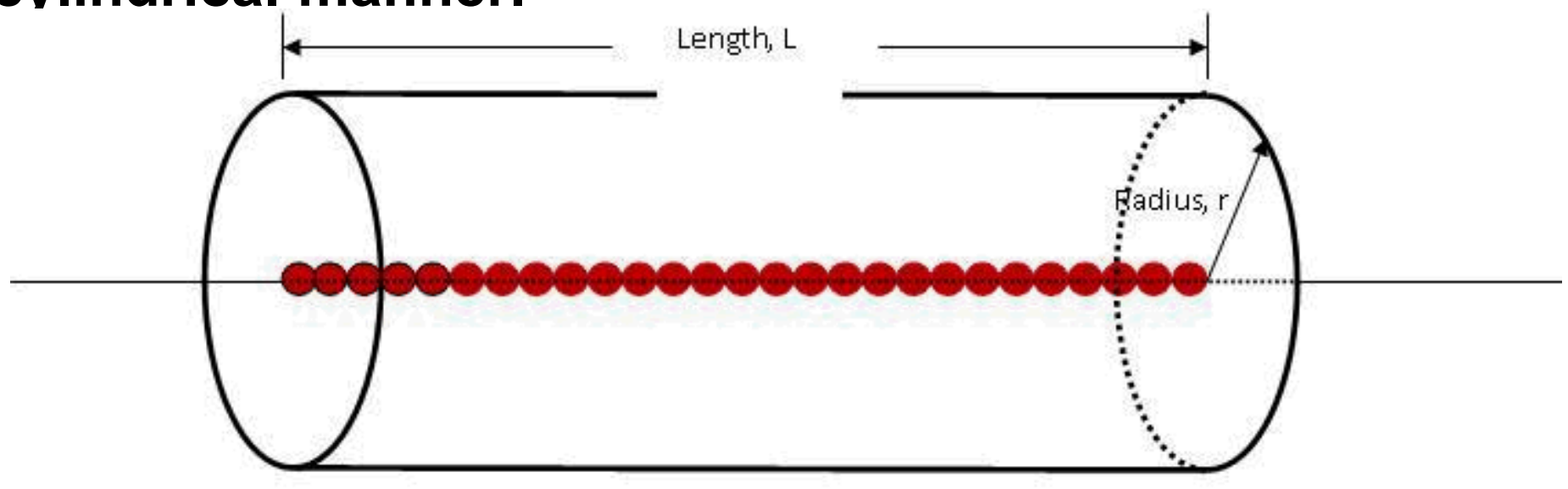

Area $=2 \pi r l$

- Therefore, as you move away from the source, you decrease the dose rate by $1 / \mathrm{r}$ and the ISL does not work. 


\section{Limitations of the Inverse Square Law}

- Point Source vs. Line Source

- Can you determine a line source vs point source? YES!

- From a distance, a line source appears to be a point source with respect to the ISL

- But, at a critical distance, the radiological field begins to transform

- This distance is roughly half of the length of the line source

- So, if a line source is 12 feet in length, it will resemble a point source up to 6 feet away. Within 6 feet, it takes on a line source 


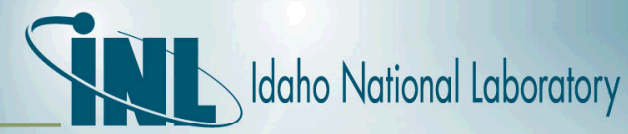

\section{Limitations of the Inverse Square Law}

- Take a 12-foot long line source that has a total curie content of $500 \mathrm{Ci}$ Co60.

- To make matters simple, assume there are $41.7 \mathrm{Ci}$ located in the center of each 1-foot section (red dots).

- As you can see, at 1 foot of distance from the center of the rod, you are not 1-foot away from each $41.7 \mathrm{Ci}$ source.

- So, although you have $500 \mathrm{Ci}$ of Co-60, it doesn't look like you have that much because it is spread out over a long distance.

- If this were a single point source, the dose rate at 1 -foot would be $7595 \mathrm{R} / \mathrm{hr}$.

- Instead, the dose rate at 1-foot for this 12-foot line source is $1772 \mathrm{R} / \mathrm{hr}$

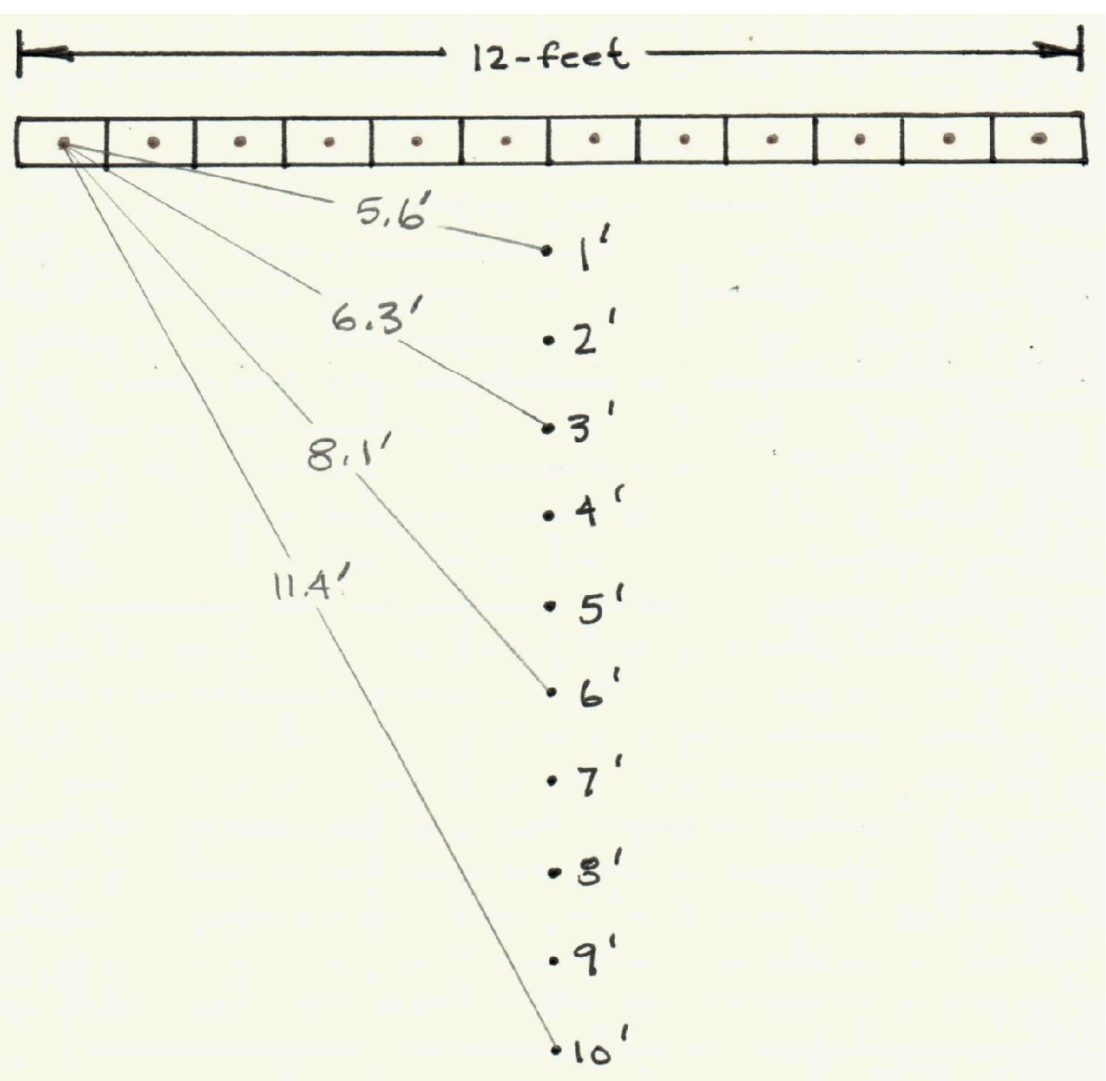




\section{Limitations of the Inverse Square Law}

\begin{tabular}{|c|c|c|c|c|c|c|c|c|}
\hline \multirow[b]{3}{*}{ Dist, $\mathrm{ft}$} & \multirow{2}{*}{\multicolumn{2}{|c|}{$\begin{array}{l}\text { Point } \\
\text { Source }\end{array}$}} & \multicolumn{6}{|c|}{ 12-foot Line Source } \\
\hline & & & \multicolumn{2}{|c|}{ Center Approach } & \multicolumn{2}{|c|}{ Perp End Approach } & \multicolumn{2}{|c|}{ End Approach } \\
\hline & $\mathrm{R} / \mathrm{hr}$ & \begin{tabular}{|c|} 
Fact \\
or \\
\end{tabular} & $\mathrm{R} / \mathrm{hr}$ & Factor & $\mathrm{R} / \mathrm{hr}$ & Factor & $\mathrm{R} / \mathrm{hr}$ & Factor \\
\hline 1 & 7595.0 & & 1772.3 & & 1439.4 & & 543.0 & \\
\hline 2 & 1898.8 & & 790.9 & & 589.1 & & 265.2 & \\
\hline 3 & 843.9 & 4 & 467.5 & 2.8 & 343.7 & 2.6 & 166.9 & 2.4 \\
\hline 4 & 474.7 & & 311.2 & & 232.3 & & 117.9 & \\
\hline 5 & 303.8 & & 222.0 & & 169.9 & & 88.9 & \\
\hline 6 & 211.0 & 4 & 165.8 & 3.4 & 130.5 & 3.0 & 70.1 & 2.7 \\
\hline 7 & 155.0 & & 128.2 & & 103.7 & & 57.0 & \\
\hline 8 & 118.7 & & 101.9 & & 84.4 & & 47.4 & \\
\hline 9 & 93.8 & & 82.7 & & 70.0 & & 40.1 & \\
\hline 10 & 76.0 & & 68.4 & & 59.0 & & 34.5 & \\
\hline 11 & 62.8 & & 57.5 & & 50.4 & & 30.0 & \\
\hline 12 & 52.7 & 4 & 48.9 & 3.8 & 43.5 & 3.5 & 26.3 & 3.0 \\
\hline 15 & 33.8 & 4 & 32.1 & 3.9 & 29.5 & 3.6 & 18.7 & 3.1 \\
\hline 17 & 26.3 & 4 & 25.3 & 3.9 & 23.6 & 3.7 & 15.4 & 3.2 \\
\hline 24 & 13.2 & & 12.9 & & 12.4 & & 8.8 & \\
\hline 30 & 8.4 & & 8.3 & & 8.1 & & 6.0 & \\
\hline 34 & 6.6 & & 6.5 & & 6.4 & & 4.9 & \\
\hline
\end{tabular}

Line Source vs. Point Source

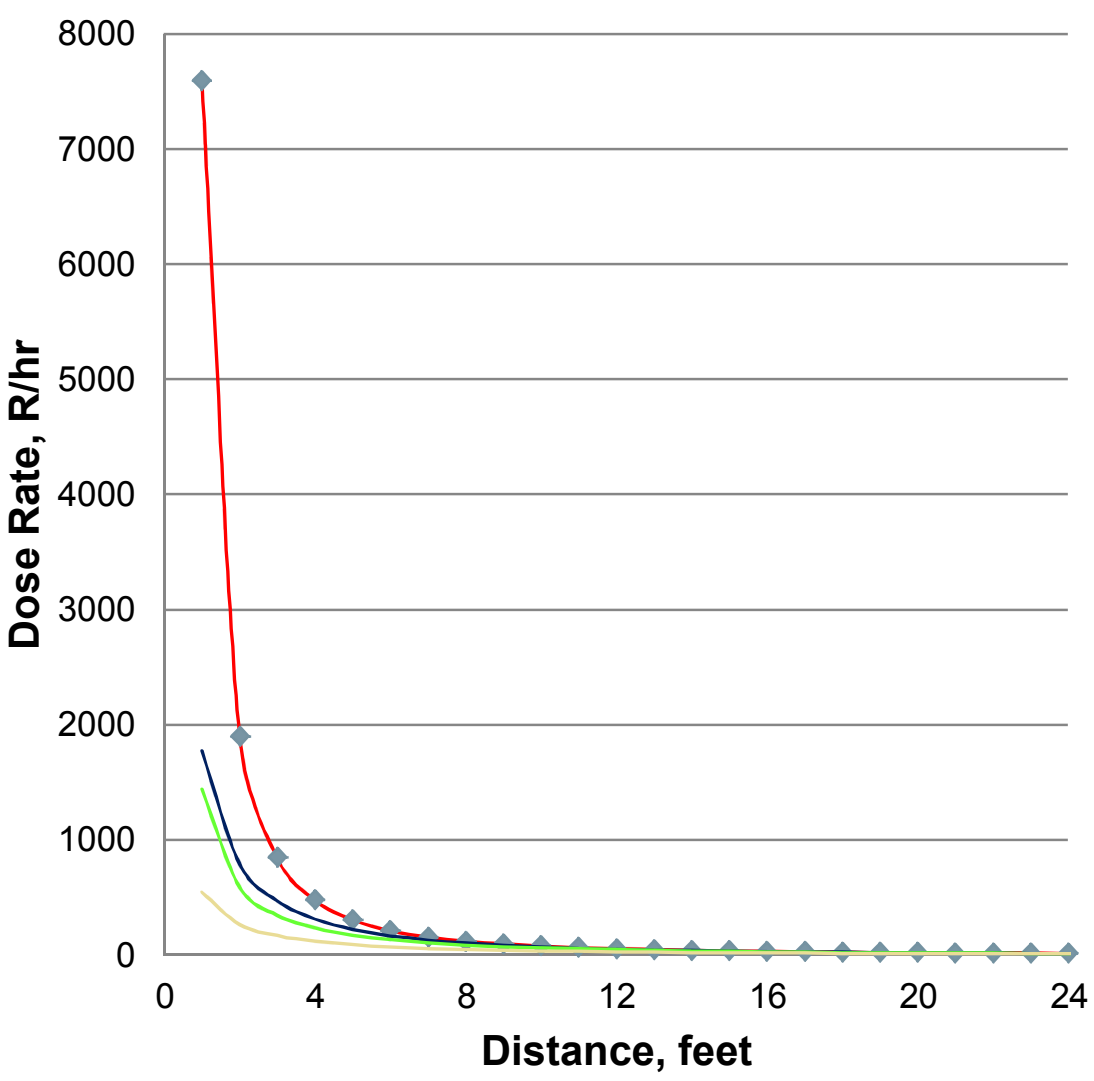

$\longrightarrow$ - Point Source

-12' Line Source Middle Approach

_12' Line Source Perp End Approach

_12' Line Source End Approach 


\section{Activity}

- The activity of a substance tells us how many disintegrations, or how many unstable nuclei decay in a second and emit radiation

- A unit of activity is called a Curie

$$
\begin{aligned}
& A=\frac{X}{\Gamma} \\
& \mathbf{A}=\mathbf{C} \mathbf{i} \\
& X=(R / H r) \\
& \Gamma=\left(\frac{R}{H r} x C i\right) @ 30 \mathrm{~cm} \text { or } 1 \text { Foot } \\
& \text { "gamma constant" }
\end{aligned}
$$

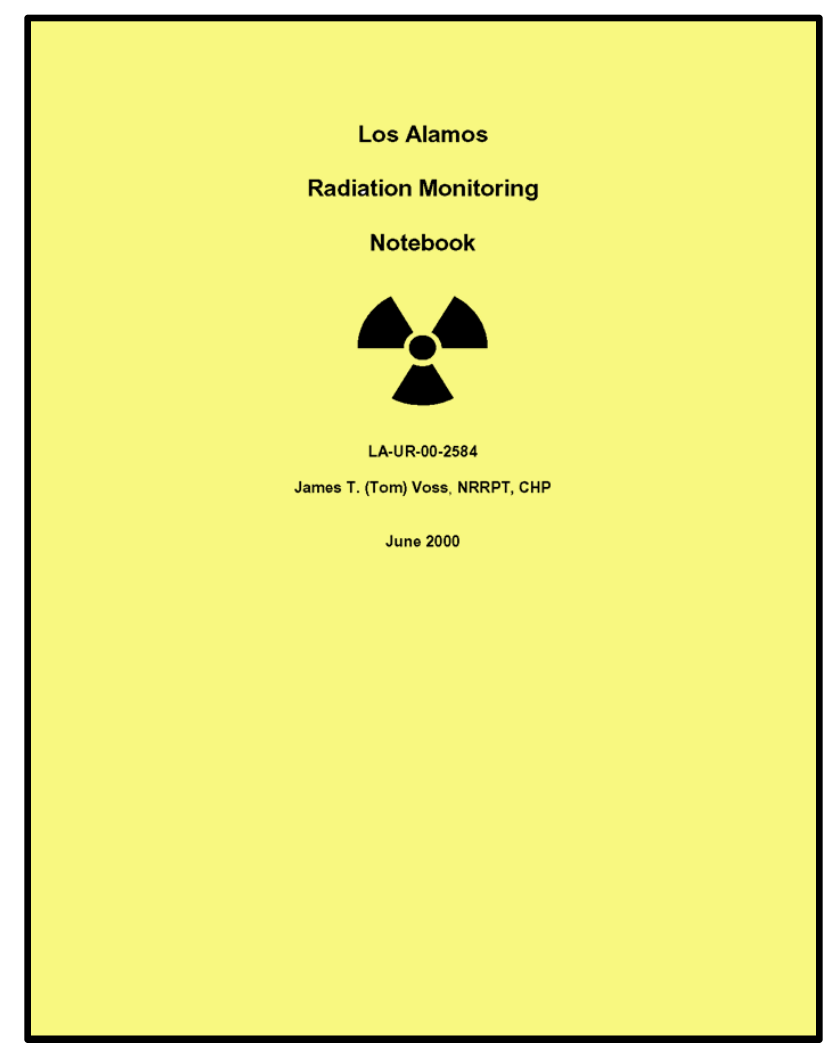

Page 31 


\section{q}

\section{Activity}

- Given a cobalt-60 source that is putting out $300 \mathrm{mR} / \mathrm{hr}$ at $1 \mathrm{foot}$, what is the activity in $\mathrm{Ci}$ ?

- Use LANL handbook (p33)

- $A=(R / h r) /(R / h r-C i)$

- $A=\frac{0.3 \frac{R}{h r}}{15.19 \frac{R}{h r}-C i}$

- $\mathrm{A}=0.02 \mathrm{Ci}$ 


\section{Half-Value Layers}

- Half-Value Layer (HVL) is defined as, "the thickness of material needed to reduce a known dose or dose rate down by $1 / 2$ of its original value"

- But the concept of HVL is not that easy because:

- HVL varies due to both;

- The energy of the gamma ray and,

- The material used for shielding

- Material composition

- The denser the material, the less is needed to decrease the dose by $1 / 2$

- This means that materials like lead, tungsten and uranium make the best shielding materials because of their density and,

- Materials like water, concrete and wood make poor shielding materials 


\section{Half-Value Layers}

- Gamma energy is how energetic (intense) the gamma ray is, and the higher the energy, the more material is needed in order to reduce the dose by $1 / 2$.

- A good analogy for this is a bullet fired from a 50-caliber machine gun has a higher energy than a bullet fired from a 22caliber handgun. Therefore, it will take a thicker material to stop the 50-caliber bullet than the 22-caliber bullet.

- Each isotope has an intrinsic gamma energy or range of gamma energies associated with it.

- For example:

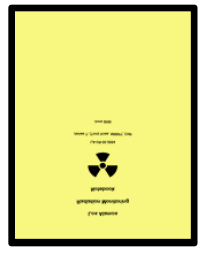

Pg. 53

- ${ }^{75} \mathrm{Se}-215 \mathrm{keV}$ ( $\gamma$ energy peaks at $97,121,136,265,280$, 401)

- ${ }^{192} \mathrm{Ir}-352 \mathrm{keV} \quad(\gamma$ energy peaks at 296, 308, 317, 468)

- ${ }^{137} \mathrm{Cs}-662 \mathrm{keV}$ (one $\gamma$ energy peak)

- ${ }^{60} \mathrm{Co}-1253 \mathrm{keV}(\gamma$ energy peaks at 1173 and 1332) 


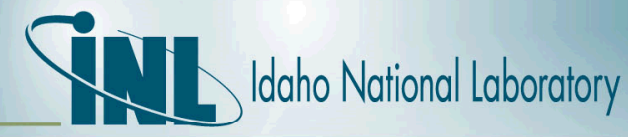

\section{Half-Value Layers}

- Example $-{ }^{75} \mathrm{Se}$

- $1500 \mathrm{mR} / \mathrm{hr}{ }^{75} \mathrm{Se}$ source

\begin{tabular}{|c|c|c|c|c|c|c|c|c|c|}
\hline \multirow[b]{2}{*}{ Energy, keV } & \multirow[b]{2}{*}{$\begin{array}{c}\% \text {-time } \\
\text { Contrib. }\end{array}$} & \multirow[b]{2}{*}{$\begin{array}{c}\% \text {-Overall } \\
\text { Contrib. }\end{array}$} & \multirow[b]{2}{*}{$\begin{array}{l}\text { Dose Rate } \\
\text { Contrib. }\end{array}$} & \multirow[b]{2}{*}{ HVL, $\mathbf{c m}$} & \multicolumn{5}{|c|}{ Lead Shield Thickness, cm } \\
\hline & & & & & 0.025 & 0.05 & 0.086 & 0.213 & 0.379 \\
\hline 96.7 & 3.41 & 1.9 & 29 & 0.025 & 14.5 & 7.3 & 2.7 & 0.08 & 0.0008 \\
\hline 121.1 & 17.15 & 9.7 & 146 & 0.037 & 91.4 & 57.2 & 29.1 & 2.7 & 0.12 \\
\hline 136 & 59.2 & 33.6 & 504 & 0.046 & 346 & 237 & 138 & 20.4 & 1.7 \\
\hline 265 & 59.8 & 33.9 & 509 & 0.155 & 455 & 407 & 346 & 197 & 93.3 \\
\hline 280 & 25.2 & 14.3 & 214 & 0.173 & 194 & 176 & 152 & 91.4 & 46.9 \\
\hline 401 & 11.51 & 6.5 & 98 & 0.343 & 93 & 89 & 82.3 & 63.7 & 45.5 \\
\hline Totals & 176.27 & 100 & 1500 & & 1193.9 & 973.5 & 750 & 375 & 187.5 \\
\hline
\end{tabular}

- You can see from the data that $1 \mathrm{HVL}$ is equal to $0.086 \mathrm{~cm}$. But, the second HVL requires $0.213 \mathrm{~cm}$ lead, which is more than twice the original HVL and the third is more than three times the original HVL 


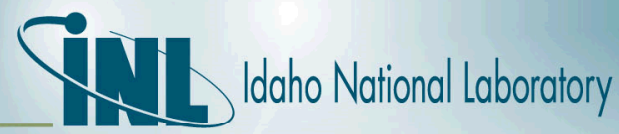

\section{Half-Value Layers}

- The general equation used to calculate shielding effects using HVLs is:

$$
X=X_{0} \times\left(\frac{1}{2}\right)^{n}
$$

where:

$X_{0}$ is the original dose rate

$$
n=\frac{\text { Thickness of Shielding }}{\text { Half }- \text { Value Layer }}
$$




\section{Half-Value Layers}

- Given that the HVL for ${ }^{137} \mathrm{Cs}(662 \mathrm{keV})$ is;

$-.52 \mathrm{~cm}$ lead (see page 53)

- Solve the following problems:

- A ${ }^{137}$ Cs source is giving off a dose rate of $20 \mathrm{R} / \mathrm{hr}$ at 2 feet. Calculate the dose rate at 2 feet if:

- $5 \mathrm{~cm}$ of lead is placed in front of it 


\section{Half-Value Layers}

- Calculate exponent:

$$
\mathrm{n}=5 \mathrm{~cm} / 0.52 \mathrm{~cm}=10
$$

- $\mathrm{X}=20 \mathrm{R} / \mathrm{hr}(1 / 2)^{10}$

- $\mathrm{X}=0.019 \mathrm{R} / \mathrm{hr}$

$-19 \mathrm{mR} / \mathrm{hr}$ 


\section{Problem}

Break into groups:

Work the problems on paper by hand and with RadPro Calculator, compare the results as you go

Work the problems as a group, use what ever resources you have

You will stay in these groups for the remainder of the course 


\section{Problem}

- During a stand-by mission your team is directed to respond to a suspicious detonation, radiological alarms have gone off.

-What are your dose rate and total dose alarm settings? Discuss within your small group.

- How will you determine if you are at risk for spreading contamination? What equipment will you use to identify and measure the level of contamination? Discuss within your small group.

- Is this an emergency? and if so how does that affect your dose rate and total dose limits? Discus within you small group. 


\section{Problem}

- As you enter the blast area your dose rate at 20 feet from the suspected detonation site is $20 \mathrm{mR} / \mathrm{hr}$

- Are you at risk?

- What should the reading be at 10 feet from the suspected location? And how long can you stay at 10 feet given a total dose

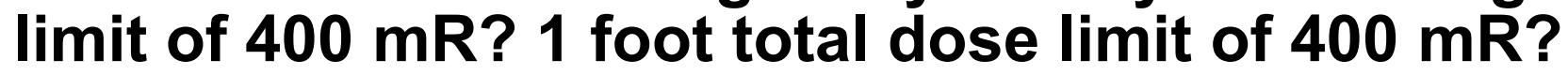

- $80 \mathrm{mR} / \mathrm{hr} @ 10$ feet

- 10 feet $=5$ hours

- Dose rate @ 1 foot = 8R/hr

- 1 foot $=3$ minutes 


\section{Problem}

- You move to 10 feet of the suspected detonation site and your dose rate is now $80 \mathrm{mR} / \mathrm{hr}$

- Do you suspect a point source, line source or plane source?

- Point source

- Have you located the detonation site?

- Yes, the device failed to spread contamination 


\section{Problem}

- You determine that the detonation failed to disperse the radioactive material. You identify that the isotope is Cesium-137. Given your two dose rate readings and isotope what is the activity?

- $A=X / \Gamma, X$ was solved at 1 foot during the previous question, page 33 for $\Gamma$

- $A=8 R / h r / 4.44 R / h r-C i$

- $\mathrm{A}=1.8 \mathrm{Ci}$

- Is this just a $\gamma$ hazard? What is the $\mathrm{KeV}$ for this isotope?

- Page 31, Ba137m

- Is the answer the same in RadPro?

- RadPro is usually more conservative 


\section{Problem}

- Your WMD Coordinator has arrived on scene, he wants to know what the dose rate will be at one foot if they place a $5 \mathrm{~cm}$ lead sheet over it and how much time they will have to collect evidence if their total dose limit is $\mathbf{4 0 0} \mathrm{mR}$.

- 2 part problem: Half Value Layer and Stay Time

- HVL see page $53, X=8 R / h r X(1 / 2)^{10}=7.8 \mathrm{mR} / \mathrm{hr}$

- Stay Time $=400 \mathrm{mR} / 7.8 \mathrm{mR} / \mathrm{hr}=51.2$ hours 


\section{Questions ???}

